\title{
Using Text-to-Voice/Word Prediction Software to Enable Adolescent Learners
}

\author{
Glenda Black \\ Schulich School of Education, Nipissing University
}

\begin{abstract}
Intermediate teachers are challenged with teaching students of all academic abilities in their inclusive classrooms. To address this problem, teachers are creating universally designed classrooms to provide equal access to learning experiences in all aspects of the curriculum. In this differentiated learning environment teachers eliminate barriers to learning by using assistive technology, specifically, textto-voice/word prediction software. The purpose of this mixed method research study was to explore and describe the perceptions and experiences of students and teachers in a school-based assistive technology improvement initiative in an Ontario K-8 school. Quantitative data was collected from eight Grade 8 learning disabled students: The Ontario Comprehension Assessment (OCA) was used to measure students' performance. Following quantitative data analysis, semistructured interviews were conducted with the eight students and a focus group interview was conducted with the three grade 8 teachers who participated in the initiative. The data revealed a startling improvement in the measurement of students' learning outcomes. When using the software, intermediate students are more able to effectively communicate their understanding
\end{abstract}

\section{Introduction}

As Mr. Ryan ${ }^{1}$, the special education teacher, walked into the grade 8 classroom he was immediately aware of the conversational buzz among the students. In groups of four, the students are engaged in a literacy activity. The classroom teacher, Ms. Ross, who was conferencing with one of the students at one of the group of desks looked up from the paper she was reading with a student, smiled and nodded hello to Mr. Ryan. Scanning the classroom, Mr. Ryan noted eight students were using computers, six had laptops at their desks and two were on the desktop computers at the back of the classroom. Four of the students working on the computers were formally identified as Learning Disabled (LD) students. Cody, one of the identified LD students welcomed Mr. Ryan by pulling off his headphones and motioning him over to his desk. Shaking his head to move his hair back into his style of choice, Cody points to the computer screen and shares with Mr. Ryan his response to an article he read that morning using the text to voice/word prediction computer software.

Listening to Cody, Mr. Ryan reminded himself that earlier in the term Cody was considered a reluctant reader and generally a disengaged student. More recently, with the implementation of the assistive technology - text to voice/word predictor computer software in their grade 8 classroom, Cody had gained the confidence to work on literacy assignments in the classroom along side his peers rather than moving to the special education room to complete assignments. In their continuing effort to improve their students' literacy skills, Mr. Ross, Ms. Ryan, and the other two grade 8 teachers in the school volunteered to take part in a school-based Assistive Technology (AT) improvement initiative. All the teachers agreed that the outcomes of the sixweek initiative were startling.

Cody's classroom is among the growing number of universally designed classrooms where teachers provide equal access to learning experiences to all

\footnotetext{
${ }^{1}$ All names have been changed to protect the privacy of the participants.
} 
aspects of the curriculum. Members of the Expert Panel on Literacy and Numeracy Instruction for Students with Special Education Needs emphasized the belief that if teachers plan their instructional program using the structures of Universal Design for Learning (UDL) and differentiated instruction the learning needs for all students will be met [1]. The UDL orientation is constructed on the notion that designing an instructional program for a target group, students with special learning needs, benefits all students. Researchers declare that the UDL approach "is a strategy to eliminate barriers to learning that students may encounter" [2]. A teacher using differentiated instruction to create a classroom is sensitive to the needs of every student by providing an active student-centered, safe and secure environment [3]. In a differentiated learning environment the individual learning needs of all the students are considered.

\section{Theoretical Framework}

\subsection{Assistive Technology}

Teachers have the most significant influence on student achievement [4] and research supports the statement that effective literacy skills are critical to the academic success of students [1]. The implications for teachers, therefore, are to ensure the foundation of their literacy programming is built on an "evidence-based" process [5]. In recent years there has been an increased interest to gather evidence on the effectiveness of AT by measuring the outcomes of assistive technology [6, 7, 8, \& 9]. Nevertheless, evidence to support the measurement of student outcomes is underrepresented in the literature. Edyburn [10] suggests that evidence to support outcome measures of AT is in its infancy. Edyburn [10] continued to explain that research related to AT is evolving. With the introduction of AT in the past twenty years, researchers focused on "only two stakeholders: the consumer and the provider" [10, para.8]. This research project contributes evidence that implementing AT practices improves student outcomes.

The Individuals with Disabilities Education Act (IDEA) defines an assistive technology device (ATD) as "any item, piece of equipment, or product system, whether acquired commercially off the shelf, modified, or customized, that is used to increase, maintain, or improve functional capabilities of a child with a disability" [11, PL, 300.5]. Assistive technology is one resource that teachers can use in their literacy instruction. Technology does not replace good instruction; rather it makes good instruction more accessible to children with learning challenges. Used in the classroom, AT has the potential to increase students' productivity, break down information into more manageable pieces, provide immediate and informative feedback, supply a voice to listen, an ear to record, and replaces books and pencils for children with physical challenges. Assistive technology, specifically text to voice/word predictor software, provides a supportive role in teaching. Built into instructional practices, AT is advantageous for all students, not only the students with special needs. Indeed, with the consistent use of curricular supports like text to voice/word predictor improves the quality of instruction for all learners by engaging all students in the regular curriculum [12]. Embedding text to voice/word predictor software into instructional practices has the potential to improve academic achievement and increase students' participation [13], enhance students' self esteem and confidence [14], improve the quality of their written work and reads what they cannot read independently [8], and provide teachers with assessment information [15].

\subsection{Benefits of Assistive Technology}

2.2.1. Independence. Providing students access to assistive technology levels the academic playing field for all students. Cavalier, Ferretti, and Okolo [16, para. 16] equated assistive technology as a cognitive prosthetic, "technology corrects an impairment for individuals with disabilities and can help them access the general curriculum”. Students are not as dependent on others to assist them in their reading and writing. Assistive technology breaks down barriers for students with disabilities as it allows students to become more independent. In turn, the technology provides the students with real world opportunities to pursue careers in the ever-growing field of technology. Alper [16] identifies two noteworthy benefits to students using assistive technology:

(1) Disability is a natural part of the human experience and in no way diminishes the right of individuals to (a) live independently; (b) enjoy selfdetermination and make choices; (c) benefit from an education; (d) pursue meaningful careers; and (e) enjoy full inclusion and integration in the economic, political, social, cultural, and educational mainstream of society in the United States. (2) Technology has become one of the primary engines for economic activity, education, and innovation in the Nation, and throughout the world [16, para.12]. Technology is embedded in our society. Enhancing students' understanding and proficiency with technology allows them to become more responsible and contributing citizens.

Text-to-voice software has audio-feedback built into the operating system. "Thus writing is scaffolded with an oral reading, fostering metacognition and allowing students to monitor their composing” [17, 2008, para.10]. Caverly [17, para.10] continues to explain the benefits of the 
software stating, "assistive technology provides access and assistance for students who might not otherwise have success with writing”.

2.2.2. Motivation. Teachers who apply creativity to their curriculum by accessing AT "creates an educational environment that fosters selfdevelopment, cooperation, positive communications, and personalization of information" [14, para.1]. Khek, Lim, and Zhong [14] acknowledged that AT has the potential to scaffold learning and the flexibility to tailor the curriculum to maximize the learning experience. Emotionally, assistive technology can increase motivation and self esteem and improve "student's self-concepts and academic performance. ALT can increase their learning enthusiasm and enrich their interest in their academic endeavors" [14, para.10].

Providing assistive technology to enhance students' learning, increases motivation, well-being and feelings of personal accomplishment are aligned with social cognitive theory. Nelson [18] supports the idea that the most reliable motivational construct or predictor of behavior in the classroom is selfefficacy. In Nelson's words, “Human beings' level of motivation, affective states, and actions are based more on what they believe than on what is objectively true. Self-efficacy serves as the foundation for human motivation, well-being, and personal accomplishment” [18, para.1]. In education, self-efficacy is a more reliable predictor of behavioral outcomes than any other incentive construct [18]. Nelson [18] supports the notion that assistive technology in the classroom is an example of universal design of learning. In a universally designed classroom, teachers support all students by providing learners with equitable learning experiences to ensure equal access to the curriculum.

2.2.3. Improves Quality of Work. Assistive technology, specifically text to voice/word predictor, has the potential to improve significantly students' work by addressing students' reading and writing challenges. For example, the software has the capability to assist with the following writing tasks: (a) word processing can address fine motor difficulties and reduce messy work; (b) spellchecking tools can reduce some spelling difficulties; (c) The ability to place graphs and charts in assignments allows students to produce a better quality of assignment, reinforcing the value of published writing; (d) cut-and-paste features in word processors allow students to manipulate text easily when editing, saving valuable time and effort. The physical process and effort of rewriting work can be laborious, time consuming, and fatiguing for some students [1]. In addition to the reading and writing supports, AT expands immediate feedback and individual learning for students and performance tracking and assessment opportunities for teachers [14].

\subsection{Barriers to Assistive Technology}

Alpher [16] highlights barriers to successful AT implementation such as inequitable access to technology, cost of equipment, and lack of professional development for educators. Some families and schools do not have access to technology because of limited financial resources. Lack of professional training for teachers and educational assistants is an essential obstacle to address for the successful implementation of assistive technology. The educators servicing the students need to know how and when to use the technology. Implementation of any type of AT requires the practical professional development of all staff members using the technology.

The educators using the technology require professional development that provides them with instruction on the purpose of the technology and how to use the technology. Dyal, Carpenter, and Wright [19, para.4] propose, "Meaningful, standards-based professional development should be connected to how assistive technology is utilized to promote successful learning outcomes within the general education curriculum. Time spent in professional development equips professionals with innovative and evidence-based practices in the area of assistive technology”.

\section{Methodology}

To enhance the reliability and validity, the current study employed a mixed-method approach of conducting research. The data was collected over six weeks beginning with the quantitative data, the administration of the pre-assessment, the Ontario Comprehension Assessment (OCA) [20]. Formative assessment data was collected from eight grade 8 learning disabled students from three different classrooms in a JK-8 school in southern Ontario. During the six week cycle, a text to voice/word prediction software intervention plan was implemented in the three grade eight classes and all the teachers in the school were provided with on and off site professional development opportunities related to using assistive technology. Upon completion of the quantitative data analysis, individual semi-structured interviews were conducted with the eight Grade 8 students and a focus group interview was conducted with the three grade 8 classroom teachers. The study sought to address the following research questions: (a) What types of experiences, if any, do grade 8 students with learning disabilities have using assistive technology to communicate their reading connections in writing? (b) What types of experiences, if any, do Grade 8 
teachers have using assistive technology in their grade 8 classroom?

\subsection{Ontario Comprehension Assessment}

The Ontario Comprehension Assessment (OCA) was the best suited instrument for measuring the students' connections made in their reading through their writing. The instrument links assessment to explicit reading strategy and skills instruction and is aligned with the Ontario literacy curriculum [20]. The OCA was administered to all grade 8 students as the pre and post assessment of their reading comprehension. Following the administration of the pre-assessment of the OCA, the text to voice/word predictor technology intervention plan was implemented in the three grade 8 classes within a 6 week cycle to enable the LD students in the classes to more effectively communicate the connections made in their reading through their writing. The teachers used a range of instructional strategies to improve students' ability to more effectively communicate their reading comprehension through writing. For example, the teachers read aloud and modeled for students various strategies to extract pertinent information from textbooks, newspaper articles, and websites. Students were given individual copies of the articles. After highlighting the relevant points they explored numerous ways to organize the information. Independently, students were asked to read a newspaper article that focused on the current economic situation in the province. The article was linked to the World Economics unit in Geography. The students formally identified as LD and those who wished to access the technology were provided with laptop computers in the classroom to listen to the articles using the text to voice software with the word prediction, read back, highlighter, and extractor features.

The students wrote their answer into the text to voice software and were able to self edit their writing. Students came together in groups and were asked to identify the main topic of the article. The ideas were then shared during a whole class lesson. As an equity consideration, and following the tenets of universal design of learning, the text to voice/word prediction software was made available to all grade eight students, including those not formally identified with special learning needs. Students used the text to voice/word prediction software to assist in their understanding of increasingly complex and difficult text by summarizing important ideas and explaining how the details support the main idea. The OCA was used to measure the students' progress over time while using the assistive technology: 1 diagnostic (preassessment), 2 formative, and 1 summative (postassessment).

\subsection{Professional Development}

A month prior to the assistive technology intervention plan, the Assistive Technology Learning Center (ATLC) teacher facilitated text to voice/word software workshops for all the teachers and educational assistants in the school during lunch recess and after school. These professional development sessions allowed the teachers to ask questions and receive clarification before they moved through the intervention cycle. In addition, the grade 8 teachers attended an after school text to voice/word predictor software workshop at the Assistive Technology Learning Center (ATLC), an off site classroom. Students with learning disabilities attend the ATLC for a 12-week session to improve their proficiency using AT. The grade 8 teachers were provided time to observed the ATLC program during the day while students were in the class. All the teachers and educational assistants in the school were given the same opportunity to be released from class to observe the ATLC.

\subsection{Interviews}

The target population for this project was a convenience sample of three grade 8 teachers, 85 grade students and eight learning disabled students who participated in the project's data collection from a JK-8 school in southern Ontario. The school is in an urban setting with approximately 700 students. Following the administration of the OCA post assessment the eight grade 8 learning disabled students were individually interviewed. The discussion concentrated on the perceptions of the students to better understand the impact of using the assistive technology. Each student was asked to share 'two stars and a wish', provide both positive and negative aspects related to using the text to voice/word prediction software in the classroom. Similarly, the grade 8 teachers in a focus group interview were asked to share their positive and negative perceptions of implementing the assistive technology in the classroom. The focus group's synergy allowed the participants to draw on the other member's experiences to brainstorm collectively. The recording and transcription of the focus group interview allowed the participants to review the accuracy of the transcripts.

\section{Data Analysis}

\subsection{Student Assessment Scores (OLA)}

The pre and post Ontario Comprehensive Assessment data were analyzed to determine what influence the use of text to voice/word prediction technology had as an accommodation on the LD 
students in three grade 8 classes to enable them to more effectively communicate the connections made in their reading through their writing. The OLA assessment scores were calculated to establish any change in the students' ability to more effectively communicate their reading comprehension through writing with the adoption of the AT in the classroom.

As Table 1 illustrates, the writing assessment scores of the eight grade $8 \mathrm{LD}$ students show a startling increase in their ability to communicate their reading comprehension over the course of the intervention. The students were assigned the diagnostic assessment prior to the opportunity to use the AT to complete their writing assignments to communicate the connections made in their reading through their writing. The teachers gave direct instruction and modeled writing non-fiction writing on a number of occasions (approximately eight separate occasions). At the same time, the teachers instructed the students on how to use the text to voice/word prediction software for writing and editing their work. The scores recorded in the table below are a summary of the four assessments.

The results indicate that all the students' writing scores increased significantly using the text to voice/word prediction software. The boys' diagnostic scores were lower than the girls. The boys and girls summative scores were similar. However, the boys had the most significant increase between the diagnostic (pre-assessment) and the summative (post-assessment) task.

\section{Table 1. Summary of Student Assessment Scores}

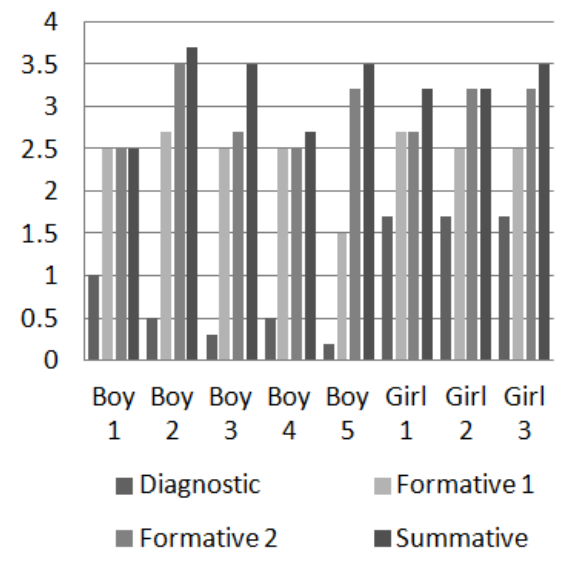

\subsection{Student Interviews}

Each of the eight grade 8 LD students were asked to share "Two Stars and Wish" when working with the text to voice/word prediction software - what did they like and not like about using the assistive technology.
Two Stars. The positive comments focused on the 'read' feature. They liked how the program read their work back to them. For example, Boy 5 stated, "When I typed something and it was read back - it was not how I read it - it is how someone else would read it." Girl 2 stated, "I liked that it read it back to you - when you read it back it sounds different. Boy 4 noted that he was able to type the words faster than he could write the words. Therefore, he was able to get all his thoughts down because he typed them right into the voice/word predictor software program. Girl 1 liked the word bank feature, "If you don't know how to spell it - there are different options and you can see what looks right.” Boy 2 also noted that he like the predictor feature, "when you type it - it gave you a couple of words because it goes quicker I am a slow typer."

Wish. All of the students noted that the feature they would change was the voice. Boy 5 noted that the "pronunciation of the words was not always appropriate." Boy 4 explained that the voice, "creeped me out. I did not like it. The voices were too computerish." Boy 1 noted that the software voice was robotic sounding - he too thought it was "creepy."

Some "wishes" or negative comments were around the formatting of the software. Boy 5 noted, "The formatting of how it was done - it was not working for me - I am used to word and the software does not have the same functions." He continued by stating, "I wish that they made one for older grades this one looked like it was for the younger kids." Girl 2 noted that she had difficulty with all the features, "It was confusing because there are so many different things to do like the voice, how fast it was." Boy 5 also suggested the formatting of the software be revised. He "wished that they made a program for older grades.”

\subsection{Focus Group Interview with Teachers}

In a focus group interview the teachers were asked to give their perceptions of implementing the assistive technology in their instructional practice for the six-week intervention. The teachers shared their experiences and perceptions both negative and positive on integrating text to voice/word predictor software into their teaching repertoire. The most common concern was the teachers' frustration with the technology. On occasion, some of the computers did not work or there were not enough computers available for all the students who wished to use the technology. Printing was not available for all computers in the classroom (laptops could print, but the desktop computers were not connected to the printer). If the students used the software in the computer lab the student work could not be saved or printed if the printer was not functional, which meant 
that the teacher had to review the students' work on the computer.

Despite the technical difficulties with the technology, the teachers believed the benefits offset the problems with the technology. The most significant benefit was "the students' ability to hear their work and edit their own publishing." Another teacher added, "When the technology is working students comment that they can really see where they need to edit.” All the teachers noted that the assistive technology improved the quality of the LD students' completed work. In addition, the teachers discussed how the learning disabled students in their classrooms became more confident and independent learners when they used the assistive technology.

During the discussion, the teachers noted that going into the intervention cycle they were not confident in their ability to use AT into their teaching practices. However, with continued practice and their eagerness to participate in the inquiry, their AT skills improved. The teachers indicated that they would continue to use AT in their teaching practices.

\section{Discussion}

Combining the significant increase in the Ontario Comprehension Assessment scores and the positive responses from the eight grade 8 learning disabled students and their teachers in the interviews, the implementation of text to voice/word predictor software was a highly effective literacy strategy for the adolescent learners. The consistent improvement in the OCA scores from the diagnostic to summative and students' and teachers' affirmative comments provide evidence that the students were more able to effectively communicate their reading comprehension through writing with the adoption of the AT in the classroom.

The purpose of this mixed method research study was to explore and describe the perceptions and experiences of students and teachers in a schoolbased assistive technology improvement initiative. The empirical data from the present research study contributes to the dialogue regarding AT in several key areas. First, the analysis from the current study provides evidence to support the positive affects on LD students' performance in literacy skills. Previous research has measuring the outcomes of AT software $[6,7,8, \& 9]$.

The data collected from this study strengthens the claims of AT's effectiveness to improve academic achievement. This research supports previous research that using assistive technology improves the quality of students' written work and reads what they cannot read independently [8]. At the same time providing teachers with assessment information [15]. Another variable this research supports is the idea that students gain motivation for academic challenges [14].
Second and currently in practice, the study provides insight into the practical application of AT in the classroom with an emphasis on school leaders developing supports to overcome the obstacles that prevent the effective use of AT. Third, software developers would benefit from the data collected from the students' interviews on the software's features. The students repeatedly mentioned the sound of the voice as an area for improvement.

\section{Implications}

The current study provides evidence to support the notion that assistive technology is a powerful accommodation that has the potential to improve student achievement. Allowing students access to text to voice/word prediction software has the potential to reduce the gap in achievement for those students who for whatever reason need extra help. Previous research supports the idea that AT builds on individual strengths, students gain motivation, accomplish higher rates of learning, improve the quality of written work, and complete academic tasks more independently, including tasks that they might not otherwise be able to handle unaided.

\section{Recommendations}

The data collected from this school based initiative contributes evidence to promoting LD students to use of AT to improve students' academic achievement. More evidence needs to be collected to assist struggling learners to more effectively measure the learning outcomes of using AT. To advance professional knowledge of AT, collecting and analyzing student performance and perception data similar to this project is essential.

The teachers who participated in this schoolbased intervention were eager to improve their instructional repertoire by using AT in the classroom. Not all teachers embrace technology with the same intensity. School leaders need to be aware that teachers are at various stages of adapting technology into their programming. By providing professional development opportunities within the school, technological support, and be open to teachers' suggestions on how to make using the technology more user friendly teachers may be more willing to accept technology as a valuable curricular support. Assistive technology is a powerful accommodation that has the potential to significantly reduce the gap in achievement for those groups of students who for whatever reason need extra help. Using this curricular support increases student success thereby, reducing the number of students at risk in our schools. 


\section{References}

[1] Ontario Ministry of Education (OME). Education for all: The report of the Expert Panel on literacy and numeracy instruction for student with special education needs, kindergarten to grade 6, Ministry of Education, Toronto, ON, 2005. Retrieved from http://www.edu.gov.on.ca.

[2] L. J. Lieberman, R. K. Lytle, and J. A. Clarcq, “Getting it right from the start: employing the universal design for learning approach to curriculum; Universal design for learning means planning ahead for the inclusion of all students. The Journal of Physical Education, Recreation \& Dance, 79(2), 2008, pp. 1-58.

[3] C. A. Tomlinson, and S. D. Allan, Leadership for differentiating schools and classrooms. Alexandria, VA: Association for Supervision and Curriculum Development, 2000.

[4] R. Marzano, D. Picketing, and J. Pollack, Classroom Instruction That Works: Research-based Strategies For Increasing Student Achievement, Association for Supervision and Curriculum Development, Alexandria, VA, 2001.

[5] P. J. Stanovich, and K. E. Stanovich, Using research and reason in education: How teachers can use scientifically based research to make curricular and instructional decisions, U.S. Department of Education, Washington, DC, 2003

[6] L. Anderson-Inman, "Supported eText: Literacy scaffolding for students with disabilities". Journal of Special Education Technology, 24(3), 2009, pp. 1-7.

[7] M. E. Bausch, and M. J. Ault, "Assistive technology implementation plan: A tool for improving outcomes", Teaching Exceptional Children, 41(1), 2008, pp. 6-14.

[8] D. L. Edyburn, "Technology-enhanced reading performance: defining a research agenda”, Reading Research Quarterly, 42(1), 2007.

[9] H. Koester, and C. DiGiovine, "Gathering and apply evidence in computer access services",

Closing the Gap, 26(5), 2007, pp. 21-23.

[13] E. McLaren, M. Bausch, M. Jones, and M. Ault, "Collaboration strategies reported by teachers providing assistive technology services", Journal of Special Education Technology, 22(4), 2007, pp. 16-30.

[14] C., Khek, J., Lim, and Y. Zhong, "Facilitating students with special needs in mainstream schools: an exploratory study of assistive learning technologies (ALT)", International Journal of Web-Based Learning and Teaching Technologies, 2006, pp. 56-75.

[15] C. E. Wissick, and J. E. Gardner, "Conducting assessments in technology needs: From assessment to implementation", Assessment for Effective Intervention, 33(2), 2008, pp. 78-93.

[16] S. Alper, "Assistive technology for individuals with disabilities: a review and synthesis of the literature", Journal of Special Education Technology, 21(2), 2006, pp. 47-69.

[17] D. C. Caverly, "Techtalk: assistive technology for writing”, Journal of Developmental Education, 31(3), 2008, pp. 36-37.

[18] B. Nelson, “On your mark, get set, wait! Are your teacher candidates prepared to embed assistive technology in teaching and learning?”, College Student Journal, 40(3), 2006, pp. 485-495.

[19] B. Nelson, “On your mark, get set, wait! Are your teacher candidates prepared to embed assistive technology in teaching and learning?”, College Student Journal, 40(3), 2006, pp. 485-495.

[20] Ontario Comprehension Assessment, Ontario Comprehension Assessment. New Market, ON: Pearson Education Canada, 2008, Retrieved from www.pearsoned.ca/school/oca/. 